\title{
Shift work, social class, and ischaemic heart disease in middle aged and elderly men; a 22 year follow up in the Copenhagen male study
}

\author{
Henrik Bøggild, Poul Suadicani, Hans Ole Hein, Finn Gyntelberg
}

Centre for Working

Time Research,

Department of

Occupational

Medicine, Aalborg

Regional Hospital,

Denmark

H Bøggild

The Copenhagen Male Study, Epidemiological Research Unit, Department of

Occupational and

Environmental

Medicine, Bispebjerg

University Hospital,

Denmark

P Suadicani

$\mathrm{H} \mathrm{O}$ Hein

F Gyntelberg

Copenhagen County Centre of Preventive Medicine, Medical Department C Glostrup University Hospital, Denmark $\mathrm{H} \mathrm{O}$ Hein

Correspondence to: Henrik Bøggild, Department of Occupational Medicine, Aalborg Regional Hospital,

Havrevangen 1, Postbox 561, DK-9100 Aalborg,

Denmark. Telephone 0045 96313400 ; fax 00459631 34 01; email hb@aas.nja.dk

Accepted 17 May 1999

\begin{abstract}
Objectives-Shift work has been associated with an increased risk of ischaemic heart disease (IHD). Most published studies have had potential problems with confounding by social class. This study explores shift work as a risk factor for IHD after controlling for social class.

Methods-The Copenhagen male study is a prospective cohort study established in 1970-1 comprising 5249 men aged 40-59. Information obtained included working time, social class, and risk factors for IHD. A second baseline was obtained in 1985-6. The cohort was followed up for 22 years through hospital discharge registers for IHD, and cause of death was recovered from death certificates.

Results-One fifth of the cohort was shift working at entry with a significantly larger proportion of shift workers in lower social classes. Risk of IHD and all cause mortality over 22 years, adjusted for age only, for age and social class, and finally for age, social class, smoking, fitness, height, weight, and sleep disturbances, did not differ between shift and day workers. The relative risk of IHD, adjusted for age and social class was 1.0 (95\% confidence interval (95\% CI) 0.9-1.2). Men being shift workers in both 1971 and 1985 had the
\end{abstract}

Table 1 Characteristics of men with self reported shift work, night work, or irregular working hours and men with day work in 1970-1

\begin{tabular}{|c|c|c|}
\hline & $\begin{array}{l}\text { Shift work } \\
(n=1123)\end{array}$ & $\begin{array}{l}\text { Day work } \\
(n=4084)\end{array}$ \\
\hline \multicolumn{3}{|l|}{ Lifestyle factors: } \\
\hline Alcohol users (\%) & 66.3 & 66.2 \\
\hline Alcoholic beverages/week among alcohol users (n) & 17.7 & $16.8^{\star}$ \\
\hline Smokers $(\%)$ & 76.1 & 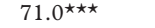 \\
\hline Tobacco smoked/day among smokers (g) & 17.1 & $15.7^{\star \star \star}$ \\
\hline Low leisure time physical activity (\%) & 15.5 & 17.8 \\
\hline Fitness value, $\mathrm{V}_{\mathrm{O} 2} \operatorname{Max}_{\mathrm{p}}$ (mean (SD)) & $33.4(7.3)$ & $32.7(7.2)^{\star \star}$ \\
\hline Sleep, 6-9 h/day (\%) & 70.3 & $79.1^{\star \star \star}$ \\
\hline \multicolumn{3}{|l|}{ Clinical or paraclinical variables (mean (SD)): } \\
\hline Height $(\mathrm{cm})$ & $174.0(6.1)$ & $174.6(6.6)^{\star \star}$ \\
\hline Weight $(\mathrm{kg})$ & $78.0(10.3)$ & $76.9(10.2)^{\star \star}$ \\
\hline Systolic blood pressure $(\mathrm{mm} \mathrm{Hg})$ & $136 \quad(20)$ & $135(19)$ \\
\hline Diastolic blood pressure (mm Hg) & $83 \quad(12)$ & $83(12)$ \\
\hline \multicolumn{3}{|l|}{ Health variables $(\%)$ : } \\
\hline Peptic ulcer history & 8.8 & 8.8 \\
\hline Hypertension treatment & 1.2 & 2 \\
\hline Non-insulin dependent diabetes & 1.1 & 0.8 \\
\hline History of cancer & 1 & 1.1 \\
\hline Regular use of medicine & 13.4 & 15.1 \\
\hline History of myocardial infarction & 1.3 & 1.4 \\
\hline Angina pectoris according to Rose questionnaire & 3.3 & 3.1 \\
\hline $\begin{array}{l}\text { Intermittent claudicatio according to Rose } \\
\text { questionnaire }\end{array}$ & 2.2 & 1.9 \\
\hline \multicolumn{3}{|l|}{ Other characteristics } \\
\hline Social class III, IV, or V (\%) & 93.5 & $68.4^{\star \star \star}$ \\
\hline Age (mean (SD) y) & $47.5(5.2)$ & $48.3(5.4)^{\star \star \star}$ \\
\hline
\end{tabular}

${ }^{\star} \mathrm{p}<0.05 ;{ }^{\star \star} \mathrm{p}<0.01 ;{ }^{\star \star \star} \mathrm{p}<0.001$, by Student's $t$ test or $\chi^{2}$ analysis. same risk as ex-shift workers in an 8 years follow up from the 1985-6 baseline.

Conclusions-The present study questions shift work as an independent risk factor for IHD. The results of the study emphasise the importance of controlling adequately for the interplay of shift work and social class.

(Occup Environ Med 1999;56:640-645)

Keywords: cardiovascular diseases; social class; work schedule

Shift work has been associated with an increased risk of ischaemic heart disease (IHD) ${ }^{1-4}$ In the most recent review it was estimated that, compared with day work, shift work was associated with a relative risk of IHD of $1.4 .^{4}$

Most studies have inadequately controlled for confounding of social class and other potential confounders. Shift workers are usually unskilled or semiskilled, belonging to lower social classes than day workers. Accordingly, shift work will often be a proxy of low social class. In industrialised western countries there is an established and often very strong inverse association between social class and risk of IHD. ${ }^{5}$ Insufficient control for the underlying relation of shift work with social class might lead to substantial errors in estimates of the importance of shift work as a risk factor for IHD.

We tested the interplay of shift work, social class, and risk of IHD, after adjustment for major potential confounding risk factors for IHD.

\section{Material and methods}

1970-1 BASELINE

The Copenhagen male study was established in 1970-1. At 14 companies in Copenhagen covering the railway, public road construction, military, post, telephone, customs, national bank, and medical industry, all men between 40 and 59 years of age were invited to take part in a study of fitness and risk of cardiovascular disease; 5249 men, which was $87 \%$ of potential participants, agreed to participate.

The examination consisted of a questionnaire, a short interview, a clinical examination with measurements of height and weight, and a bicycle ergometer test. From the questionnaire, information was obtained about working conditions, including working hours, and lifestyle and general health factors (table 1). The information given in the questionnaire was clarified with each subject in the ensuing interview. 
Details on the questionnaire have already been published. ${ }^{\circ}$

The questionnaire included one question on working time. The participants were asked whether they worked irregular hours, shift work, often had night work, or whether they worked day time only. The information was confirmed during the interview. The working time information was thus dichotomised into daytime work and other working hours.

The men were divided into five social classes according to a system originally elaborated by Svalastoga, ${ }^{7}$ later adjusted by Hansen. ${ }^{8}$ This system of classification is based on education level and job position in terms of the number of subordinates. Social class I encompassed highly educated men (professionals/ executives), social class $\mathrm{V}$ men with little education (unskilled workers/semiskilled workers).

Based on information on working time in 1970-1, two cohorts were constructed. Table 1 presents characteristics of men with self reported shift work, night work, or irregular working hours (shift worker), and of men with self reported regular daytime work (day worker).

There was no difference in the proportion of self reported drinkers between the two groups; however, among drinkers shift workers drank slightly but significantly more than day working men.

Shift workers were a little younger, included a larger proportion of smokers, and among smokers they used a little more tobacco per day. The shift working group had a larger proportion of men who deviated from the 6-9 hours of sleep a day group; some shift workers slept less, some more. Also shift workers were a little shorter and weighed a little more than day workers. There was a highly significant association with social class as $>90 \%$ of shift workers belonged to the lower classes, III, IV, and V, compared with $<70 \%$ of day workers. The actual proportions were: social class I: $4.7 \%$ shift workers; II: $6.5 \%$; III: $50.4 \%$; IV: $19.0 \%$; and V: $21.0 \%$. Social class III was especially interesting as it comprised an almost equal number of subjects reporting day and shift work. This group was given particular attention in the analysis.

Table 2 presents the results of a multivariate analysis including factors bivariately associated with shift work in table 1 . As shown the strongest associations were found for social class, a deviant sleeping pattern, and use of tobacco.

Looking at social class III alone table 3 shows the occupations reported by shift and day workers. In the shift work group almost $90 \%$ of jobs were occupations inherently associated with shift work or irregular working hours. These occupations were reported by $<4 \%$ in the day work group.

Shift workers in social class III differed from shift workers in other classes on only two factors. They drank only eight alcoholic beverages a week compared with 14 in other classes and they were on average $1.5 \mathrm{~cm}$ taller.
THE 1985-6 STUDY

In 1985-6 a second baseline was established. Participants from the 1970-1 study were traced by means of the Danish Central Population Register. All survivors (except 34 emigrants) from the original cohort were invited to take part in this baseline; 3387 (75\%) agreed, their mean age was 63 years (range 53-74). Each subject was again interviewed on the basis of a previously completed comprehensive questionnaire, had blood drawn for biochemical analysis, and underwent a physical examination. In this paper only information on working time was used. Almost half of the men were retired at the time of the 1985-6 examination.

\section{END POINTS}

In 1995 a register follow up on morbidity and mortality between 1971 and 1993 was carried out. All participants were traced by means of the Danish Central Population Register. Information on hospital admissions for non-fatal acute myocardial infarction and death certificate diagnoses within the follow up period were obtained from the National Health Service register, and from the Danish Institute of Clinical Epidemiology. Both registers used the eighth revision of the international classification of diseases (ICD-8). The ICD diagnoses used were codes 410-414.

Accordingly, this study has a baseline in 1970-1 where exposure (working time schedule) and potential confounders were measured, and a second assessment of exposure in 1985-6. The analyses use the working time status in 1970-1 as the primary exposure measurement with the cohort followed up until 1993. The second measurement of exposure in 1985-6 was used for identifying groups on the basis of their schedules on both occasions, leading to six groups; day work on both occasions, shift work on both occasions, moving from shift work to day work or from day work to shift work, and having left the work force from either day or shift

Table 2 Characteristics of men with shift $(n=1123)$ and day work $(n=4084)$

\begin{tabular}{|c|c|c|}
\hline & \multicolumn{2}{|c|}{$\begin{array}{l}\text { Partial regression } \\
\text { coefficient }\end{array}$} \\
\hline $\begin{array}{l}\text { Low social class } \\
\text { Sleep, deviation from 6-7 h/day } \\
\text { Tobacco }(\mathrm{g} / \text { day) } \\
\text { Age }(\mathrm{y}) \\
\text { Weight }(\mathrm{kg}) \\
\text { Height }(\mathrm{cm}) \\
\text { Fitness value }\end{array}$ & $\begin{array}{r}0.08 \\
0.08 \\
0.07 \\
-0.06 \\
0.07 \\
-0.05 \\
0.03\end{array}$ & $\begin{array}{l}\star \star 4 \\
\star \star \\
\star \star \star \\
\star \star \\
\star \star \\
\star \star \\
\star \star \\
\star \star \\
\star \star\end{array}$ \\
\hline \multicolumn{3}{|c|}{$\begin{array}{l}{ }^{\star \star} \mathrm{p}<0.01 ;{ }^{\star \star} \mathrm{p}<0.001 \\
\text { Significant factors from table } 1 \text { are included in a forward step- } \\
\text { wise logistic regression model with the maximum likelihood } \\
\text { ratio method. Variables are presented according to entry into the } \\
\text { multivariate model. }\end{array}$} \\
\hline \multicolumn{3}{|c|}{$\begin{array}{l}\text { Table } 3 \text { Social class III only: distribution of occupations } \\
\text { among men with self reported shift work and day work (\%) }\end{array}$} \\
\hline Self reported occupation & $\begin{array}{l}\text { Shift work } \\
(n=490)\end{array}$ & $\begin{array}{l}\text { Day work } \\
(n=482)\end{array}$ \\
\hline Train guards & 33.9 & 0.6 \\
\hline Engine drivers & 40.0 & 1.0 \\
\hline Postal foremen or guards & 10.0 & 1.9 \\
\hline Firemen & 3.0 & 0.4 \\
\hline Various, mainly office workers & 12.9 & 96.1 \\
\hline
\end{tabular}


Table 4 Absolute and relative risk (95\% CI) of ischaemic heart disease (IHD) and all causes of mortality (ACM) during 22 years of follow up according to work schedule in 1970-1 (results of Cox's proportional hazards regression analysis)

\begin{tabular}{|c|c|c|c|c|c|}
\hline & \multicolumn{2}{|c|}{ Incidence $(\%(n))$} & \multirow{2}{*}{$\frac{\text { Relative risk }}{\text { Shift } v \text { day work }}$} & \multirow{2}{*}{$\frac{\text { Relative riskt }}{\text { Shift v day work }}$} & \multirow{2}{*}{$\begin{array}{l}\text { Relative risk } \neq \\
\text { Shift v day work }\end{array}$} \\
\hline & $\begin{array}{l}\text { Shift work } \\
(n=1123)\end{array}$ & $\begin{array}{l}\text { Day work } \\
(n=4084)\end{array}$ & & & \\
\hline IHD & 18.5 (208) & $19.5(798)$ & $1.0(0.8$ to 1.2$)$ & $1.0(0.9$ to 1.2$)$ & 0.9 (0.7 to 1.1$)$ \\
\hline $\mathrm{ACM}$ & $31.6(355)$ & $32.4(1324)$ & $1.1(0.9$ to 1.2$)$ & $1.1(0.9$ to 1.3$)$ & $0.9(0.8$ to 1.1$)$ \\
\hline
\end{tabular}

^Adjusted for age only.

tAdjusted for age and social class.

¥Adjusted for factors in table 2: social class, sleep (deviation from 6-7 h/day), tobacco, age, weight, height, fitness value.

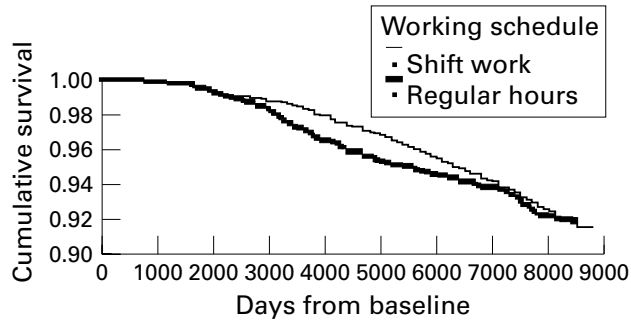

Figure 1 Death from IHD during 22 years.

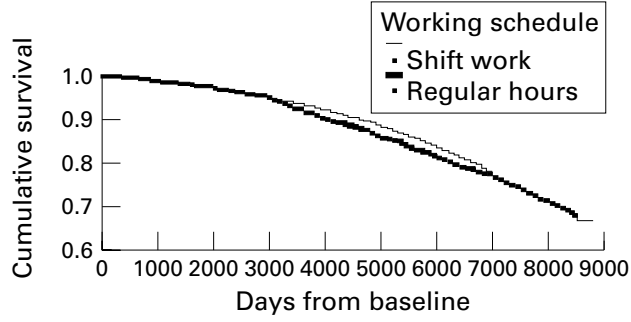

Figure 2 Death from either cause during 22 years.

work. These groups were then followed up from 1985-6 to 1993.

STATISTICAL ANALYSES

All basic analyses, Student's $t$ test, $\chi^{2}$ analyses, and the regression analyses, were performed with the SPSS statistical software for Windows. ${ }^{9}{ }^{10}$ Relative risks were estimated by $\exp (\beta)$, where $\beta$ is the hazard coefficient for the variable of interest in a Cox's proportional hazards regression model with the maximum likelihood ratio method. ${ }^{11}$ Assumptions for use of Cox's proportional hazards were met. All risk

Table 5 Cumulative incidence (n (\%)) of IHD (fatal or non-fatal) during 22 years according to work status and social class

\begin{tabular}{|c|c|c|c|c|}
\hline \multirow[b]{2}{*}{ IHD incidence 5 ( $(\%(\%))$} & \multicolumn{4}{|l|}{ Social class } \\
\hline & I and II & $I I I$ & $I V$ & $V$ \\
\hline Shift work & $8(11.3)$ & $68(14.4)$ & 79 (20.4) & $35(24.0)$ \\
\hline Day work & $168(13.5)$ & $77(16.8)$ & $348(20.7)$ & $125(23.9)$ \\
\hline
\end{tabular}

Table 6 Social class III only: absolute and relative risk (95\% CI) of ischaemic heart disease (IHD) and all causes of mortality (ACM) during 22 years of follow up according to work schedule in 1970-1 (results of Cox's proportional hazards regression analysis)

\begin{tabular}{|c|c|c|c|c|}
\hline & \multicolumn{2}{|c|}{ Incidence $(\%(n))$} & \multirow{2}{*}{$\frac{\text { Relative risk }^{\star}}{\text { Shift v day work }}$} & \multirow{2}{*}{$\begin{array}{l}\text { Relative riskt } \\
\text { Shift v day work }\end{array}$} \\
\hline & $\begin{array}{l}\text { Shift work } \\
(n=490)\end{array}$ & $\begin{array}{l}\text { Day work } \\
(n=482)\end{array}$ & & \\
\hline IHD & $15.3(75)$ & $18.5(89)$ & $0.8(0.6$ to 1.2$)$ & 0.7 (0.5 to 1.0$)$ \\
\hline $\mathrm{ACM}$ & $28.0(137)$ & $32.8(158)$ & $0.8(0.6$ to 1.1$)$ & 0.8 (0.6 to 1.1$)$ \\
\hline
\end{tabular}

*Adjusted for age only.

†Adjusted for factors in table 2 except social class: sleep (deviation from 6-7 h/day), tobacco, age, weight, height, fitness value. factor covariates in the regression analysis were those measured in 1971. A two sided probability value of $\mathrm{p}<0.05$ was taken as significant.

The study was approved by the ethics committee for medical research in the County of Copenhagen.

\section{Results}

Table 4 shows that in a 22 year follow up with a Cox's proportional hazards regression model, which takes time to event into account, there was no significant difference between shift work and day work for risk of IHD and mortality from all causes. When potential confounding factors were included in the analysis this had only minimal influence on the risk estimate, and the table shows three selected models, one where risk is adjusted only for age, one in which social class is added, and one in which all potential mediating or confounding factors that differed between the cohorts at baseline were included.

Whether looking at mortality alone or including both mortality and morbidity of IHD did not change risk estimates.

Figures 1 and 2 illustrate on a survival curve the consistency of the finding over time with the hard end points death from IHD and death from either cause. The only tendency was a slightly higher cumulative survival from IHD for shift workers in the middle of the follow up period.

Table 5 shows the strong inverse social gradient in cumulative incidences of IHD during 22 years within different social classes. It seemed to be completely independent of shift work, but highly dependent on social class.

When social class III was analysed separately (table 6), again no significant differences were found between shift and day workers in either risk of IHD or all cause mortality. Rather, there was a tendency in the opposite direction in both instances, with a slightly diminished risk for shift workers after adjustments were made for potential confounders $(\mathrm{p}=0.06)$.

Figures 3 and 4 illustrate the interplay of shift work, change in working time arrangements from 1971 to 1985 , and the subsequent risk of IHD and all cause mortality in the 8 year follow up from 1985 to 1993 . There was no increased risk for men who reported shift work in 1971 whether they changed to day work (ex-shift workers) or remained shift workers at both occasions. Shift workers having retired between 1971 and 1985-6 had a lower cumulative incidence than retired day workers, although both day and shift workers who did not want to participate in the 1985-6 study had the highest incidence.

The many shift workers in social class III and their intermediate risk of IHD would tend to diminish the importance of controlling for the underlying inverse linear gradient of social class and IHD in the cohort as a whole. We therefore reanalysed the association between shift work and risk of IHD in social classes I, II, and $\mathrm{V}$ only. Hereby a non-significantly increased risk of fatal IHD was found for shift workers with relative risk (RR) 1.31 ( $95 \%$ confidence interval (95\% CI) 0.82 to 2.11$)$. 


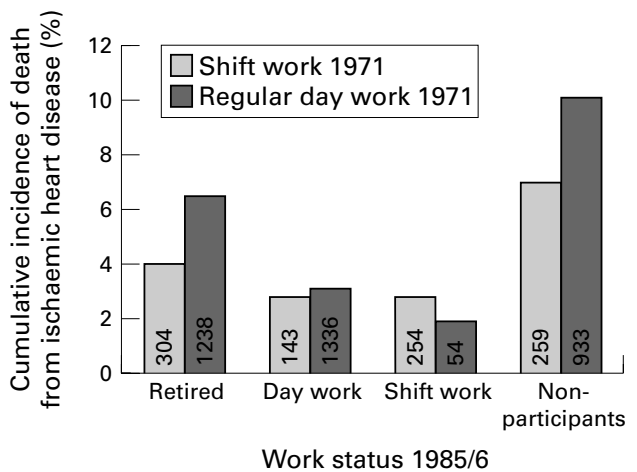

Figure 3 Cumulative incidence of death due to ischaemic heart disease 1985-6 to 1993 according to work status in 1971 and work status in 1985-6.

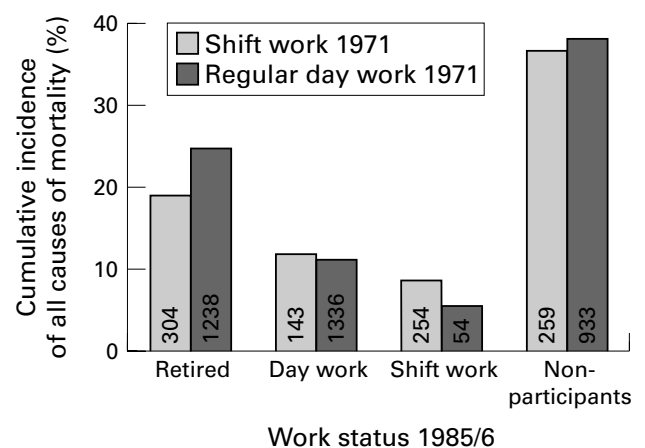

Figure 4 Cumulative incidence of all causes of mortality 1985-6 to 1993 according to work status in 1971 and work $1985-6$ to 1993 acc
status in 1985-6.

Adjustment for social class eliminated this difference completely, RR 0.96 (95\% CI 0.59 to 1.57). Corresponding values for all IHD events were: 1.25 (0.87 to 1.78$)$ and 0.95 (0.66 to 1.38 ), respectively (not shown in tables).

\section{Discussion}

This study did not support the hypothesis that shift work is an independent risk factor for the development of IHD. ${ }^{4}$ This is in accordance with three other large studies not supporting a relation. ${ }^{12-14}$ This lack of association was not explained by competing causes of death, as the same absence of association was found with death from either cause. This is consistent with the only previous study that examined the general influence of shift work on mortality. ${ }^{12}$ Shift workers who had changed to day work over 14 years had no increased risk compared with day workers who remained day workers, and no significantly increased risk compared with shift workers remaining in shift work (fig 4). This contrasts with other studies that found that workers leaving shift work are at higher risk of contracting cardiovascular diseases than shift workers remaining in shift work. ${ }^{12}{ }^{15-19}$

Could the conspicuous lack of association between shift work and IHD have been the result of selection, measurement, or confounder bias?

\section{SELECTION BIAS}

The selection of participants to the Copenhagen male study may have caused a selection of people with relatively better health than the background population of employed men in
Copenhagen. Most of the population studied were employed by large organisations with certain demands on the health of new employees. At least in one of the companies, employees were subjected to pre-employment screening for hypertension, and regular health surveillance programmes were also conducted. Exclusion of this company from the analysis did, however, not change risk estimates.

The participants were middle aged at entry into the cohort and had experienced half a working life. Starting shift work often takes place in the early working years, and some $20 \%$ of new shiftworkers leave shift work within a few years for a daytime job. ${ }^{20}$ This secondary selection process is likely to take place in the early working years, even more so as day work in many instances is used as a reward for some years of shift work. Our cohort of shift workers might thus be interpretated as a survivor population that have adjusted to the work schedule before entering the cohort. However, of five previous cohort studies that did not rely on aggregated data, three included people in the same age groups or older than this cohort, ${ }^{12} 2122$ and two of these found an increased risk of IHD in (middle aged) shift workers.

Furthermore, from a cardiovascular point of view participants are not very old at baseline, as very few people experience IHD before the age of 40 , and then there is often a genetic basis. This is in accordance with table 1 , showing that only a small proportion of men had a history of cardiovascular disease, whether day or shift workers.

\section{MEASUREMENT BIAS}

The assessment of work status was based on questionnaires at both baselines. These point estimates were validated for a part of the cohort (table 3) by comparing self assessment of working schedule with the actual job title. This validation indicated that men with shift work had been exposed to this kind of work for an extended period. That shift work seemed to be a long term exposure was further supported (fig 3) with both baselines: among men at work, two of three shift workers in 1970-1 still worked as such in 1985-6, and only a few per cent indicated that they changed from day to shift work. The workers who reported shift work both in 1971 and in 1985-6 could have changed to day work in between, but were more likely to have had at least 14 years of shift work, and thus constitute a more heavily exposed group.

The actual schedules were not reported, but the cohort was made up of men employed at 14 large private and public companies, and the shift schedules at these companies are reported to have predominantly been irregular rotating three shifts. Even so work schedules might have differed in the amount of night work ${ }^{4}$ and thus dilute an effect of shift work. An analysis taking work place into account did not show differences across the companies, suggesting that heterogeneity of shift schedules was not responsible for the result.

The assessment of end points in the Copenhagen male study has been carried out with 
information from hospital records and the Danish morbidity and mortality registers. The validity of these registers is quite high. ${ }^{23}$ Previous analyses in the Copenhagen male study have confirmed established risk factors for IHD: smoking, blood pressure, low density lipoprotein and high density lipoprotein cholesterol, physical inactivity, and alcohol consumption, indicating that the cohort is fairly representative of middle aged, white men living in industrialised societies. ${ }^{24}$

CONFOUNDER BIAS

Main risk factors for IHD were tested for (table 1). Sleep deviation, smoking, age, weight, height, fitness, and social class significantly separated shift workers from day workers and could hereby act as confounders. Most of these could also have been mediating factors, linking shift work and IHD, but controlling or not controlling for them did not greatly change the risk estimates.

Accordingly, confounder bias is an unlikely explanation for the results of this study.

\section{CONFOUNDING BY SOCIAL CLASS}

Employees working day or night, even at the same company, differ in social class, as skilled workers more often have only day or two shift schedules, but unskilled workers more often are included in three shift schedules. When possible, maintenance and repair are carried out during daytime. As shift work occurs less often in higher social classes this would tend to confound the direction of a relation. As previously published in the Copenhagen male study, a strong inverse gradient between social class and IHD existed in a 17 year follow up. ${ }^{6}$ Table 4 shows that this strong relation also existed after 22 years. In this study the distribution of shift workers within social classes was skewed with only a small proportion in social classes I and II being shift workers, half the population in class III, and one man in five in classes IV and V, indicating that the cohort was not a random sample of the shift working population, but rather-through the sampling of large companies-had an overrepresentation of lower civil servants. Accordingly, shift work itself was not only a proxy for low social class, more so for the middle class group who also had an intermediate risk of IHD. So it was not surprising that social class was but a minor confounder in an analysis of the entire cohort.

The nature of the influence of social class on the incidence of IHD is not known, but has, apart from lifestyle differences, been related to selection processes, culture, material conditions, and effects in utero or infancy. ${ }^{25}$ Differences in working conditions may play a minor part, but not to a degree that indicateed that social class might be a proxy of shift work.

Most of the previous studies that found an association between shift work and IHD have not controlled for social class. ${ }^{26-29}$ Some studies have controlled partly for social class through information on educational level or job status. ${ }^{132230}$ Only in the Helsinki heart study ${ }^{21}$ has the effect of this control been studied. Adjustment for social class in the form of restriction to blue collar work led to a decrease of the relative risk of shift work from 1.51 to 1.35 , which was no longer significant. One study has compared day and shift working nurses ${ }^{22}$ and found that a significantly increased risk of IHD persisted after adjustment for educational level of the spouse. Even so, people working at night are in many other ways different from day workers within the same occupation and social class, including differences in, for example, family life circumstances and social support, known risk factors for IHD. ${ }^{31}$

\section{Conclusion}

Most of the previous studies have found a relative risk of 1.4 for shift work and IHD, but that may have been confounded by social class. This study is the first to consider the subject in a long term cohort study with a large proportion of shift workers, many fatal and non-fatal end points, and with a comprehensive control for major confounders including social class. The results question shift work as an independent risk factor for IHD. Furthermore they emphasise the importance of controlling adequately for the interplay of shift work and social class.

1 Åkerstedt T, Knutsson A, Alfredsson L, et al. Shift work and cardiovascular disease. Scand $\mathcal{f}$ Work Environ Health 1984;10:409-14.

2 Wagner U. Schichtarbeit und ischämische herzkrankheit (Shift work and ischemic heart disease (no English summary)). Z Arztl Fortbild (fena) 1989;83:229-33.

3 Kristensen TS. Cardiovascular diseases and the work Kristensen TS. Cardiovascular diseases and the work
environment: a critical review of the epidemiologic literature on nonchemical factors. Scand $\mathcal{f}$ Work Environ literature on nonchemical

4 Bøggild H, Knutsson A. Shift work, risk factors and cardiovascular disease. Scand $\mathcal{f}$ Work Environ Health 1999;25:8599

5 Syme SL. Social class and cardiovascular disease. In: OrthGomér K, Schneiderman N, eds. Behavioral medicine approaches to cardiovascular disease prevention. Mahwah: Lawrence Erlbaum Associates, 1996;43-50.

6 Hein HO, Suadicani P, Gyntelberg F. Ischaemic heart disease incidence by social class and form of smoking: the Copenhagen male study: 17 years' follow up. F Intern Med 1992;231:477-83.

7 Svalastoga K. Prestige, class and mobility. Copenhagen: Munksgaard, 1959.

8 Hansen EJ. Socialgrupper i Danmark. Copenhagen: SocialHansen EJ. Socialgrupper $i$
forskningsinstituttet, 1984 .

9 Norusis MJ, SPSS. SPSS for windows: base system users guide, Norusis MJ, SPSS. SPSS for windows.
release 6.0. Chicago: SPSS, 1993.

10 Norusis MJ, SPSS. SPSS advanced statistics 6.1. Chicago: SPSS, 1994.

11 Cox DR. Regression models and life-tables. Fournal of the Royal Statistical Society 1972;34:187-220.

12 Taylor PJ, Pocock SJ. Mortality of shift and day workers 1956-68. Br f Ind Med 1972;29:201-7.

3 McNamee R, Binks K, Jones S, et al. Shiftwork and mortality from ischaemic heart disease. Occup Environ Med 1996;53:367-73.

14 Steenland K, Fine L. Shift work, shift change, and risk of death from heart disease at work. Am $\mathcal{F}$ Ind Med 1996;29:278-81.

15 Aanonsen A. Shift work and health. København: Scandinavian University Books, Munksgaard, 1964.

6 Koller M. Health risks related to shift work. Int Arch Occup Environ Health 1983;53:59-75.

17 Michel-Briand C, Chopard JL, Guiot A, et al. The pathological consequences of shift work in retired workers. In: Reinberg A, Vieux N, Andlauer P, eds. Night and shift work: biological and social aspects. Oxford: Pergamon Press, 1980;399-407.

18 Koller M, Kundi M, Cervinka R. Field studies of shift work at an Austrian oil refinery. I: health and psychosocial wellbeing of workers who drop out of shiftwork. Ergonomics 1978;21:835-47.

19 Thiis-Evensen E. Skiftarbeid og helse: II (Shift work and health: II). Porsgrunn: Norsk Hydro, 1956.

20 Monk TH, Folkard S. Making shift work tolerable. London: Taylor and Francis, 1992.

21 Tenkanen L, Sjöblom T, Kalimo R, et al. Shift work, occupation and coronary heart disease over 6 years of follow up in the Helsinki heart study. Scand $\mathcal{F}$ Work Environ Health 1997;23:257-65.

22 Kawachi I, Colditz GA, Stampfer MJ, et al. Prospective study of shift work and risk of coronary heart disease in women. Circulation 1995;92:3178-82. 
23 Mabeck CE, Wickmann B. Cause of death and death certificates. Assessment of the diagnoses in 373 death cercertificates. Assessment of the diagnoses in 373 death
tificates (in Danish). Ugeskr Laeger 1980;142:257-61.

24 Suadicani P, Hein HO, Gyntelberg F. Strong mediators of social inequalities in risk of ischaemic heart disease: a 6-year follow-up in the Copenhagen male study. Int 7 Epidemiol 1997;26:516-22.

25 Smith GD, Blane D, Bartley M. Explanations for socioeconomic differentials in mortality: evidence from Britain and elsewhere. European Fournal of Public Health 1994;4: 131-44.

26 Alfredsson L, Karasek R, Theorell T. Myocardial infarction risk and psychosocial work environment: an analysis of the male Swedish work force. Soc Sci Med 1982;16:463-467.

27 Alfredsson L, Spetz C, Theorell T. Type of occupation and near-future hospitalization for myocardial infarction and some other diagnoses. Int f Epidemiol 1985;14:378-88.
28 Tüchsen F. Working hours and ischaemic heart diseases in Danish men; A 4-year cohort study of hospitalization. Int $\mathcal{F}$ Epidemiol 1993;22:215-21

29 Åkerstedt T, Alfredsson L, Theorell T. Arbetstid och sjukdom: en studie med aggregerade data (Work hours and disease: an analysis with aggregated data). Stressforskningsrapport no 190. Stockholm: Statens institut för psykosocial miljömedicin, 1987.

30 Knutsson A, Hallqvist J, Reuterwall C, et al. Shift work and myocardial infarction: a case-control study. Occup Environ Med 1999;56:46-50.

31 Orth-Gomér K. International epidemiological evidence for a relationship between social support and cardiovascular disease. In: Shumaker SA, Czajkowski SM, eds. Social support and cardiovascular disease. New York: Plenum Press, 1994;97-117. 